Research Paper

\title{
Randomized, controlled clinical pilot study of venous leg ulcers treated with using two types of shockwave therapy
}

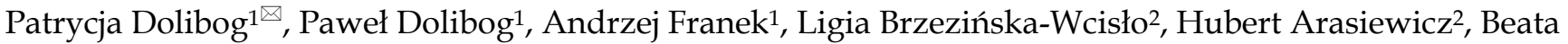
Wróbel ${ }^{1}$, Daria Chmielewska ${ }^{3}$, Jacek Ziaja ${ }^{4}$, Edward Błaszczak ${ }^{1}$

1. Chair and Department of Medical Biophysics, School of Medicine in Katowice, Medical University of Silesia

2. Department of Dermatology, School of Medicine in Katowice, Medical University of Silesia

3. Department of Basics of Physiotherapy, Faculty of Physiotherapy, Academy of Physical Education in Katowice

4. Department of General, Vascular and Transplant Surgery, School of Medicine in Katowice, Medical University of Silesia

$\triangle$ Corresponding author: Patrycja Dolibog,pdolibog@sum.edu.pl

(C) Ivyspring International Publisher. This is an open access article distributed under the terms of the Creative Commons Attribution (CC BY-NC) license (https://creativecommons.org/licenses/by-nc/4.0/). See http://ivyspring.com/terms for full terms and conditions.

Received: 2018.04.11; Accepted: 2018.06.30; Published: 2018.08.06

\begin{abstract}
Background. Venous leg ulcers are difficult to heal wounds. The basis of their physiotherapeutic treatment is compression therapy. However, for many years, the search for additional or other methods to supplement the treatment of venous ulcers, which would shorten the duration of treatment, is underway. One of such methods is the shockwave therapy.

Methods. The purpose of our study was to compare radial shockwave therapy (R-ESWT) with focused shockwave therapy (F-ESWT) in venous leg ulcers treatment.

Patients were randomly assigned to tree groups. In the first group the radial shockwave therapy $\left(0.17 \mathrm{~m} / \mathrm{mm}^{2}, 100\right.$ impulses $\left./ \mathrm{cm}^{2}, 5 \mathrm{~Hz}\right)$, in the second group the focused shockwave therapy $\left(0.173 \mathrm{~mJ} / \mathrm{mm}^{2}, 100\right.$ impulses $\left./ \mathrm{cm}^{2}, 5 \mathrm{~Hz}\right)$ was used and in third group standard care was used. Patients in shockwave therapy groups were given 6 treatments at five-day intervals. Total area, circumference, Gilman index, maximum length and maximum width of ulcers were measured. The patients from the third group wet gauze dressing with saline and gently compressing elastic bandages were used (standard wound care SWC).

Results. Analysis of the results shows that a complete cure of ulcers was achieved in $35 \%$ of patients who were treated with radial shockwave, $26 \%$ of patients with focused shockwave used. There is statistically significant difference between the standard care and radial shockwave therapy as well as between the standard care and focused shockwave therapy. There is no statistically significant difference between the use of radial and focused shockwave in the treatment of venous leg ulcers $(p>0.05)$.

Conclusion. There is no statistically significant difference between the use of radial and focused shockwave in the treatment of venous leg ulcers. Treatment of venous leg ulcers with shockwaves is more effective than the standard wound care.
\end{abstract}

Key words: radial shockwave therapy, focused shockwave therapy, venous leg ulcers, wound healing

\section{Introduction}

Chronic venous insufficiency is the most common form of venous disease that occurs in $1 \%$ of the population predominantly among women than men, in a 2: 1 ratio. The frequency of its occurrence increases with age [1-4].
Venous leg ulcers are the most common result of a chronic venous insufficiency. It is estimated that venous leg ulcers in Western Europe are present in $0.3 \%-1 \%$ of the adult population and it number increases to $3-4 \%$ in the range of $65-80$ years $[3,5,6]$. 
Leg ulcers are the serious medical and socioeconomic problem because of the chronicity. These wounds contribute to lowering the quality of life due to physical condition (sleep quality, ability to work, mobility), psychological (appearance, concentration), social (interpersonal) and environmental (housing, financial resources, medical care) [7].

Compression therapy, leg elevation and wet dressings are the standard care for venous ulcers and chronic venous insufficiency. Pharmacological treatment is taking edema-protective agents (phlebotropic drugs), pentoxifylline or aspirin; surgical management include debridement, skin grafting, human skin equivalent and surgery for venous insufficiency. In addition, to support healing, applied physical methods such as high voltage electrostimulation, direct current electrostimulation, low-level laser therapy, ultrasound therapy, low frequency magnetic therapy, hyperbaric oxygen therapy $[8,9,10]$.

In recent years, shockwave is used for soft tissue defects treatment. It is a mechanical wave on the front of which the pressure increases from the value of which the environment has to the maximum value $(100 \mathrm{MPa})$ in time of nanoseconds $(<10 \mathrm{~ns})$. The pressure then decreases exponentially to achieving the smaller value than the initial value (air) and it increases to the initial value. The whole cycle takes about $10 \mathrm{~ms}$. The frequency of the generated wave is in the range of $16 \mathrm{~Hz}$ to $20 \mathrm{MHz}$. The propagation speed of the shockwave is greater than the propagation velocity of the acoustic wave in the material [11-14].

The therapeutic effects of the shockwave depends largely on the amount of energy released during the treatment, and therefore one of the most important parameter is the energy concentrated in the unit area $\left(\mathrm{mJ} / \mathrm{mm}^{2}\right)$, referred to as surface energy density. Due to the energy the shockwave can be divided into a low-energy $<0.2 \mathrm{~mJ} / \mathrm{mm}^{2}$ (LESWT low energy shockwave therapy), and the high energy of $>0.2 \mathrm{~mJ} / \mathrm{mm}^{2}$ (HESWT - high energy shockwave therapy) [15-19].

The shockwave is usually generated in a device outside a patient's body, which is in english naming ESWT (Extracorporeal Shockwave Therapy), or shorter SWT (Shockwave Therapy). Then the wave is delivered to the destination by using a corresponding transducer focusing the wave by using overlays (acoustic lens) focusing F-ESWT (Focused Extracorporeal Shockwave Therapy) or distracting D-ESWT (defocused, Unfocused - Extracorporeal Shockwave Therapy). Other transducer can deliver radial wave ESWT (R-ESWT) or flat (planar) wave ESWT (P-ESWT) [11-19].
Scientific publications describe the use of focused and unfocused shockwave treatment results in accelerated healing and regeneration of diverse ethology wounds which are the effect of increased secretion of vascular endothelial growth factor to induce neovascularization and improve blood flow to tissues. Additionally, increase in metabolic rate and initiation of cell proliferation and differentiation has been documented [by 20].

Aschermann et al. [21] used a shockwave ESWT 100 impulses per $\mathrm{cm}^{2}$, energy flux density of $0.136 \mathrm{~mJ} / \mathrm{mm}^{2}$ and a frequency of $4 \mathrm{~Hz}$ (4 times once every 3-4 weeks) to treat 60 patients with chronic leg ulcers. The authors report that they noted morphological changes and increased cell migration of keratinocytes, moreover cell-cycle regulators genes were upregulated, and proliferation induced in fibroblasts. In addition, they have observed secretion of pro-inflammatory cytokines from keratinocytes, which drive to pro-angiogenic activity of endothelial cells and wound healing.

The aim of our study was to compare two types of shockwaves therapy in venous leg ulcers (R-ESWT vs. F-ESWT) and standard care therapy. Primary study endpoints were analysis of changes of the total ulcer surface area and linear dimensions inside groups. The secondary endpoints were comparisons between all groups the number of completely healed wounds, Gilman index and percentage change of ulcer surface area and nonlinear approximation of treatment results.

\section{Material and Methods}

The studies lasted from February 2016 to December 2017. All the patients $(n=65)$ were treated in Department of Dermatology of the Medical University of Silesia, Katowice, Poland. Patients were diagnosed dermatologically and surgically. Dermatological examination included evaluation symptoms of chronic venous insufficiency (CVI) like swelling, skin discoloration and lipodermatosclerosis.

Setting and sample. All patients referred to the study underwent ultrasound examination of arteries and veins of lower limbs performed using Aloka Prosound Alpha 6 ultrasound device (Hitachi Aloka Medical, Ltd., Japan). Patients with occlusion or hemodynamically significant stenosis of limb arteries revealed in Doppler examination, as well as post-thrombotic occlusion of iliac, femoral, or popliteal veins were excluded from the study.

In all patients enrolled into the study blood flow in iliac, proximal and distal segments of femoral, popliteal, upper and lower segments of great saphenous, and small saphenous veins (including 
saphenofemoral and saphenopopliteal junctions) was examined.

Also the ankle brachial pressure index (ABPI) was established, which for all patients was higher than 1.

Exclusion criteria for the patients were: diabetes, atherosclerosis, rheumatoid arthritis, cancers, peripheral nerve damage, ventricular arrhythmia, cardiac pacemakers, and surgical treatment of ulcers, infections of the skin, pregnant, and those who reported the presence of implants from foreign bodies in the potential field of application. There were no restrictions on race, age, ulcer duration or gender.

Ethical consideration. All patients signed written agreement forms. The local Bioethics Committee of the Medical University of Silesia in protocol no KNW/0022/KB1/25/II/15 has agreed to carry out this medical experiment. All clinical investigation was conducted according to the principles expressed in the Declaration of Helsinki.

Randomization and Intervention. Patients who consented to participate in the study and gave signed informed consent were randomly allocated to three groups at using website random.org to true random number generator was generated group number, then each number was assigned to patient. A technician from Department of Medical Biophysics collected and coded data into an Excel database and export to Statistica database. Technician had no contact with any patients and could not identify them.

Patients selected for the treatment $(n=57)$ were assigned randomly into three groups $\mathrm{A}, \mathrm{B}$, and $\mathrm{C}$. Seven patients incomplete treatment (Figure 1).

Group A consisted of 17 patients, including 12 women and 5 men. The average age of the patients was $71.7 \pm 8.1$ years; the duration of the ulcers ranged from 2 to 24 months (Table 1). In this group the radial shockwave R-ESWT was used (producer: Gymna Uniphy; model: ShockMaster 500; applicator: classic $15 \mathrm{~mm}$ ) with a surface energy density $0.17 \mathrm{~mJ} / \mathrm{mm}^{2}$, 100 impulses $/ \mathrm{cm}^{2}$, frequency of $5 \mathrm{~Hz}$ and a pressure of $0.2 \mathrm{MPa}$. Directly on the wound sterile ultrasound gel was applied (Aquasonic 100) then a sterile operation foil was glued (elastoFILM Company Outline, Poland) and a gel was applied second time. The applicator's surface was disinfected after each treatment. The treatments were carried out without anesthesia. Six treatments were made at intervals of 5 days. The first three treatments were performed during the stay of patients in the hospital, and for the next three treatments, patients reported individually at the appointed time (outpatient treatment). Between treatments wet gauze dressing with saline and gently compressing elastic bandages were used. Moist dressings prevent the formation of scabs and the drying of the ulcer surface, it has a high absorption, does not adhere to the wound surface, allows painless change, protects the wound from external pollution, are non-toxic and non-allergic. In addition, they maintain a normal wound temperature close to the body temperature.

Group B consisted of 15 patients, including 7 women and 8 men. The average age of the patients was $69.1 \pm 8.9$ years; the duration of the ulcers ranged from 3 to 24 months (Table 1). In this group the focused shockwave F-ESWT was used (producer: Wolf, model: Piezowave; head: F10G4) with a surface energy density $0.173 \mathrm{~mJ} / \mathrm{mm}^{2}, 100$ impulses $/ \mathrm{cm}^{2}$, frequency of $5 \mathrm{~Hz}$ and a peak pressure of $35.6 \mathrm{MPa}$. Identical to patients from group A, for patients in group $B$ directly on the wound sterile ultrasound gel was applied (Aquasonic 100) then a sterile operation foil was glued (elastoFILM Company Outline, Poland) and a gel was applied second time. The applicator's surface was disinfected after each treatment. The treatments were carried out without anesthesia. Six treatments were made at intervals of 5 days. The first three treatments were performed during the stay of patients in the hospital, and for the next three treatments, patients reported individually at the appointed time (outpatient treatment). Between treatments wet gauze dressing with saline and gently compressing elastic bandages were used.

Group C consisted of 18 patients, including 14 women and 4 men. The average age of the patients was $67.4 \pm 8.7$ years; the duration of the ulcers ranged from 1 to 48 months (Table 1). In this group the standard care (SWC) was used. The patients wet gauze dressing with saline and gently compressing elastic bandages were used.

Treatments were performed by an experienced physiotherapist, who completed a course on management of using shockwave therapy before the study.

Measurements. Assessment of the progress promote healing of venous ulcers were performed by subjective based on the examination of the various phases of healing. Planimetry was an objective method of assessing changes in irregular surface areas of leg ulcers (digitizer Mutoh Kurta XGT). On the wound a thin, elastic, sterile, transparent sheets was applied on which the edge of the ulcer was redrawn by a permanent marker with a round tip $(0.5 \mathrm{~mm}$ diameter). Next, the projection of ulceration on the clean film was redrawn and measurements of total area, circumference, maximal length and perpendicular to it maximum width were made with using computer program (C-GEO v.4.0, Poland). Wounds were systematically photographed. 
All patients had BMI determined (body mass index) using the formula $\mathrm{BMI}=\mathrm{m} / \mathrm{h}^{2}\left[\mathrm{~kg} / \mathrm{m}^{2}\right]$

where: $\mathrm{m}$ - patient's weight in kilograms; $\mathrm{h}$ patient's height in meters.

Exceeding $30\left[\mathrm{~kg} / \mathrm{m}^{2}\right]$ BMI classifies the patient to obesity.

The measurements were performed before treatment, after each treatment, and 30 days after the last treatment. From the measured values a series of indicators were determined in order to facilitate interpretation.

Following formulas were used:

$$
\Delta \mathrm{X} \%=\left(\left(\mathrm{X}_{1}-\mathrm{X}_{\mathrm{F}}\right)^{*} 100 \%\right) / \mathrm{X}_{1}
$$

where $\Delta \mathrm{X} \%, \mathrm{X}_{1}, \mathrm{X}_{\mathrm{F}}$ are:

$\Delta S \%$ - relative change of the ulcer surface area $(\%), S_{1}, S_{F}-$ the initial and final ulcer area $\left(\mathrm{cm}^{2}\right)$;

$\Delta \mathrm{L} \%$ - relative change of the ulcer maximum length (\%), $\mathrm{L}_{1}, \mathrm{~L}_{\mathrm{F}}$ - the initial maximum and final maximum length of ulcers $(\mathrm{cm})$;

$\Delta W \%$ - relative change of the ulcer maximum width (\%), $\mathrm{W}_{1}, \mathrm{~W}_{\mathrm{F}}$ - the initial maximum and final maximum width of ulcers $(\mathrm{cm})$.

Gilman coefficient [18] $d(\mathrm{~cm})$ which has been designated for an exact evaluation of the healing process, calculated by the formula:

$$
\mathrm{d}=2^{*}\left(\mathrm{~S}_{\mathrm{F}}-\mathrm{S}_{1}\right) /\left(\mathrm{C}_{\mathrm{F}}+\mathrm{C}_{1}\right)
$$

where:

$\mathrm{S}_{1}, \mathrm{~S}_{\mathrm{F}}$ - initial and final ulcer area $\left(\mathrm{cm}^{2}\right), \mathrm{C}_{1}, \mathrm{C}_{\mathrm{F}}-$ initial and final ulcer circumference $(\mathrm{cm})$.

In order to estimate the time after which in each group, the ulcer area will be halved was using the nonlinear approximation of time treatment after which wound surface area decrease from start treatment by $50 \%$. In the first step we had to in order to ensure comparison of wound size changes in each group calculate relative wound area in each week of treatment (see equation 1). In next step, was presented the approximation was using the nonlinear equation 2.

Equation 1.

$$
S_{r e l}(\mathrm{t})=\frac{S(t)}{S(t=0)}
$$

where:

$\mathrm{S}_{\text {rel }}(\mathrm{t})$ - relative value wound surface area at each week of treatment in $\mathrm{cm}^{2}$;

$\mathrm{t}$ - week of treatment;

$S(t)$ - value wound surface area at each week of treatment in $\mathrm{cm}^{2}$ (e.g. $\mathrm{t}=0,1,2,3$ );

$S(t=0)$ - value wound surface area at start of treatment in $\mathrm{cm}^{2}$.

Equation 2.

$$
S_{\text {rel }}(\mathrm{t})=2^{\frac{-t}{T_{1 / 2}}}
$$

where:

$\mathrm{S}_{\text {rel }}(\mathrm{t})$ - relative value wound surface area at each week of treatment in $\mathrm{cm}^{2}$;

$\mathrm{t}$ - week of treatment;

$\mathrm{T}_{1 / 2}$ - approximate time in that, wound surface area should to decrease by half in relation to the beginning of treatment.

Statistical analysis. Statistical analyses were performed using the STATISTICA software (Dell Inc. 2016. Dell Statistica - data analysis software system, version 13, software.dell.com). The normality of the distribution of the data was using the Shapiro-Wilk test, which showed their distribution was not normal. To compare variables in all groups of patients were used: chi-square test of independence (the highest level of reliability). The values of the measured values were compared between groups using the ANOVA Kruskal-Wallis test and Kruskal-Wallis post-hoc test and in groups using the non-parametric Wilcoxon test for paired observations. Values two-sided significance level of $\mathrm{p}<0.05$ was considered statistically significant. Skewness and kurtosis of the measured values is not less than $|2.5|$, which means that good grades tested parameters are the arithmetic mean and standard deviation.

\section{Results}

65 patients were evaluated for inclusion in the research project. Further research excluded 2 patients with diabetic (one patient with two ulcers), 1 patient with atherosclerosis, 1 patient with rheumatoid arthritis (one patient with two ulcers), 1 patient with a pacemaker, 1 patients after surgical treatment of ulcers. Two patients refused further participation in the study without giving a reason, and 7 patients did not finish the treatment (Figure 1).

All patients were monitored for 55 days. Measurements (ulcer area, ulcer circumference, maximal length and maximal width) were performed before each treatment and 4 weeks after the last treatment. In all patients treatment was effective (Table 2, Figure 2).

Group A (radial shockwave) consisted of 17 patients, including $70 \%$ women and $30 \%$ men. In this group $30 \%$ of the respondents were smokers, and $70 \%$ of people declared that they do not smoke. Furthermore, in this group $47 \%$ of the patients were obese. Patients in group A were classified in accordance with CEAP: C6EsAs3Po - 11\%; C6EpAs4Pr - 6\%; C6EpAs4Po - 11\%; C6EpAs2,3Pr,o 24\%; C6EpAs2d14Pr,o - 24\%; C6EpAs2,3d14Pr - 24\%. Patients included in group A performed 6 shockwave treatments at five-day intervals. The first three treatments were performed during hospitalization and for the next three outpatient care were used. 


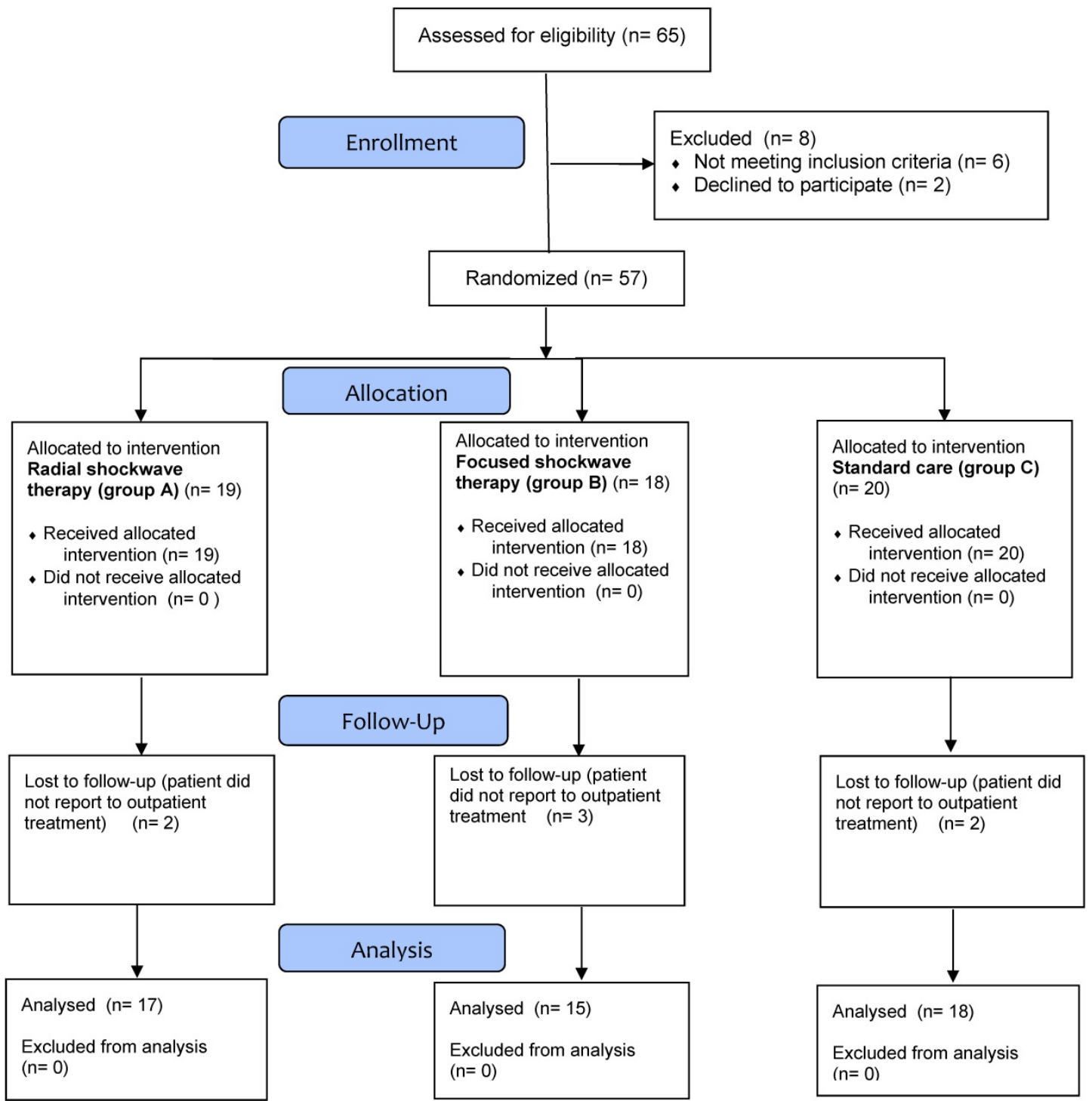

Figure 1. Allocation of patient to shockwave therapy and standard care group.

Group B (focused shockwave) consisted of 15 patients, including $47 \%$ women and $53 \%$ men. In this group, $33 \%$ of respondents were smokers, and $67 \%$ of people declared that they do not smoke. Moreover, among the group of $20 \%$ of the patients were obese. Patients from group B were classified according to CEAP: C6EpAs4Pr - 7\%; C6 EsAs3, 4Po - 40\%; C6EpAs2d14Pr,o - 33\%; C6EpAs2d14Pr - 13\%; C6EpAs2,3d14Pr $-7 \%$. As in group A, patients in group B performed 6 shockwave treatments at five-day intervals. The first three treatments were performed during hospitalization and for the next three outpatient care were used.

Group C (standard care) consisted of 18 patients, including $78 \%$ women and $22 \%$ men. In this group, $28 \%$ of respondents were smokers, and $72 \%$ of people declared that they do not smoke. Moreover, among the group of $33 \%$ of the patients were obese. Patients from group $\mathrm{C}$ were classified according to CEAP:
C6EsAs3Po - 11\%; C6EpAs4Pr - 22\%; C6EpAs4Po 17\%; C6EpAs2,3Pr,o - 11\%; C6EpAs2d14Pr,o - 22\%; C6EpAs2,3d14Pr - 17\%.

Distribution characteristics of the patients did not differ significantly between the groups A, B and C. The homogeneity of the groups was tested for the number of patients, gender, smoking, obesity chi square (NW) and the duration of ulceration, age, height and weight ANOVA Kruskal-Wallis test, and Kruskal-Wallis post-hoc test. The data after randomization were collected and presented in Table 1.

Average surface area of the ulcer before treatment in patients in group A (radial shockwave) was $5.8 \pm 7.9 \mathrm{~cm}^{2}$; while in group B (focused shockwave) it was $8.1 \pm 12.4 \mathrm{~cm}^{2}$. In group $\mathrm{C}$ (standard care), the average surface before treatment was $8.3 \pm 4.6 \mathrm{~cm}^{2}$. 
Table 1. Characteristic of the patients in groups A, B and C.

\begin{tabular}{|c|c|c|c|c|}
\hline Parameter & $\begin{array}{l}\text { Group A } \\
\text { R-ESWT }\end{array}$ & $\begin{array}{l}\text { Group B } \\
\text { F-ESWT }\end{array}$ & $\begin{array}{l}\text { Group C } \\
\text { SWC }\end{array}$ & $\mathrm{p}$ \\
\hline Ulcers (n) & 17 & 15 & 18 & \\
\hline Gender - female/male (n) & $12 / 5$ & $7 / 8$ & $14 / 4$ & $\mathrm{p}^{* *}=0.157$ \\
\hline Age (years) - mean value (SD) & $71.7(8.1)$ & $69.1(8.9)$ & $67.4(8.7)$ & $\begin{array}{l}p^{*}(A . . C)=0.303 \\
p(A \text { B })=0.732 \\
p(A \text { C })=0.439 \\
p(B \text { C) }=1\end{array}$ \\
\hline Height $(m)$ - mean value (SD) & $165.8(7.6)$ & $165.9(7.7)$ & $161.6(5.0)$ & $\begin{array}{l}\mathrm{p}^{*}(\mathrm{~A} . . \mathrm{C})=0.248 \\
\mathrm{p}(\mathrm{A} \mathrm{B})=1 \\
\mathrm{p}(\mathrm{A} \mathrm{C})=0.413 \\
\mathrm{p}(\mathrm{B} \mathrm{C})=0.547\end{array}$ \\
\hline Weight $(\mathrm{kg})$ - mean value (SD) & $82.1(11.6)$ & $79.7(11.3)$ & $72.5(18.6)$ & $\begin{array}{l}p^{*}(A . . C)=0.107 \\
p(A \text { B })=0.926 \\
p(A \text { C })=0.104 \\
p(B \text { C })=0.937\end{array}$ \\
\hline Obesity (BMI) $n<30 / n \geq 30$ & $9 / 8$ & $12 / 3$ & $12 / 6$ & $\mathrm{p}^{* *}=0.263$ \\
\hline Smokers (n) & 5 & 5 & 5 & $\mathrm{p}^{* *}=0.94$ \\
\hline Duration of disorder (months) - mean value (SD) & $8.8(7.2)$ & $9.4(6.2)$ & $11.0(13.4)$ & $\begin{array}{l}\mathrm{p}^{*}(\mathrm{~A} . . \mathrm{C})=0.621 \\
\mathrm{p}(\mathrm{A} \mathrm{B})=1 \\
\mathrm{p}(\mathrm{A} \mathrm{C})=1 \\
\mathrm{p}(\mathrm{B} \mathrm{C})=0.997\end{array}$ \\
\hline
\end{tabular}

p - Kruskal-Wallis post-hoc test;

$\mathrm{p}^{*}$ - ANOVA Kruskal-Wallis test; $\mathrm{p}^{* *}-\chi^{2}$ (chi-squared) test.

Table 2. Change in ulcer size.

\begin{tabular}{|c|c|c|c|c|}
\hline & \multirow[t]{2}{*}{ Group } & \multicolumn{2}{|l|}{ Average \pm SD } & \multirow[t]{2}{*}{$\mathrm{p}$} \\
\hline & & Before therapy & After therapy & \\
\hline \multirow[t]{3}{*}{ Total ulcer surface area $\left[\mathrm{cm}^{2}\right]$} & $\begin{array}{l}\text { R-ESWT } \\
\text { (group A) }\end{array}$ & $5.8 \pm 7.9$ & $3.5 \pm 9.1$ & 0.0129 \\
\hline & $\begin{array}{l}\text { F-ESWT } \\
\text { (group B) }\end{array}$ & $8.1 \pm 12.4$ & $6.5 \pm 11.6$ & 0.0089 \\
\hline & $\begin{array}{l}\text { SWC } \\
\text { (group C) }\end{array}$ & $8.3 \pm 4.6$ & $6.8 \pm 5.7$ & 0.0311 \\
\hline \multirow[t]{3}{*}{ Circumference $[\mathrm{cm}]$} & $\begin{array}{l}\text { R-ESWT } \\
\text { (group A) }\end{array}$ & $8.8 \pm 5.5$ & $4.8 \pm 6.1$ & 0.0010 \\
\hline & $\begin{array}{l}\text { F-ESWT } \\
\text { (group B) }\end{array}$ & $8.9 \pm 7.6$ & $7.6 \pm 8.7$ & 0.0468 \\
\hline & $\begin{array}{l}\text { SWC } \\
\text { (group C) }\end{array}$ & $11.5 \pm 4.6$ & $8.8 \pm 4.6$ & 0.0002 \\
\hline \multirow[t]{3}{*}{ Max length $[\mathrm{cm}]$} & $\begin{array}{l}\text { R-ESWT } \\
\text { (group A) }\end{array}$ & $3.2 \pm 1.9$ & $1.7 \pm 2.1$ & 0.0011 \\
\hline & $\begin{array}{l}\text { F-ESWT } \\
\text { (group B) }\end{array}$ & $3.1 \pm 2.5$ & $2.4 \pm 1.9$ & 0.0031 \\
\hline & $\begin{array}{l}\text { SWC } \\
\text { (group C) }\end{array}$ & $4.4 \pm 1.9$ & $3.5 \pm 1.9$ & 0.0006 \\
\hline \multirow[t]{3}{*}{ Max width $[\mathrm{cm}]$} & $\begin{array}{l}\text { R-ESWT } \\
\text { (group A) }\end{array}$ & $2.0 \pm 1.5$ & $1.2 \pm 2.0$ & 0.0147 \\
\hline & $\begin{array}{l}\text { F-ESWT } \\
\text { (group B) }\end{array}$ & $2.2 \pm 1.9$ & $1.9 \pm 2.2$ & 0.0145 \\
\hline & $\begin{array}{l}\text { SWC } \\
\text { (group C) }\end{array}$ & $2.7 \pm 1.1$ & $2.0 \pm 1.1$ & 0.0002 \\
\hline
\end{tabular}

(p) Wilcoxon test.

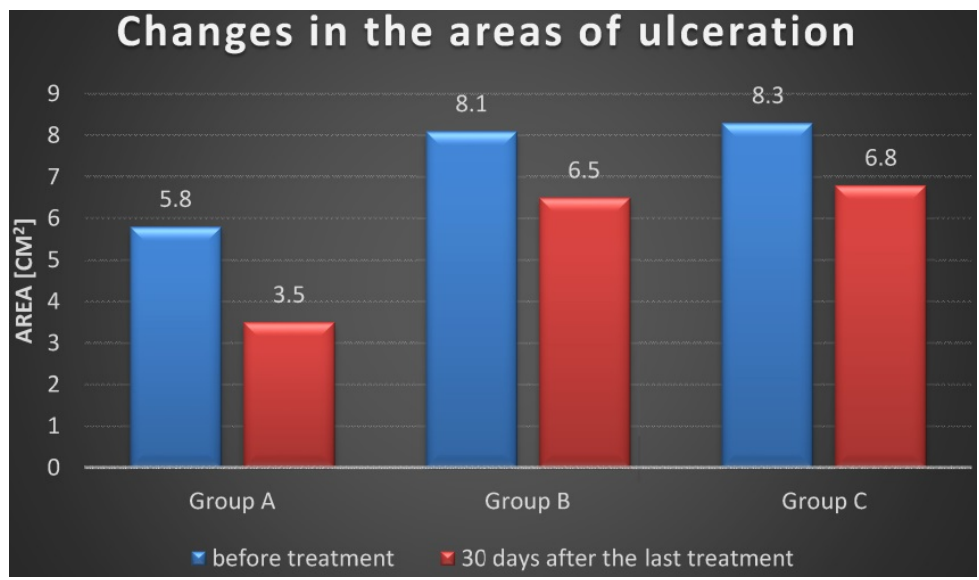

Figure 2. Changes in the areas of ulceration. Group A - R-ESWT; Group B - F-ESWT; Group C - SWC.
Average initial circumference ulcers in patients in group A was $8.8 \pm 5.5 \mathrm{~cm}$, and for patients in group $B$ it was $8.9 \pm 7.6 \mathrm{~cm}$, and for patients in group it was $11.5 \pm 4.6 \mathrm{~cm}$. The homogeneity of the groups relative to the state output of the measured parameters such as surface area, circumference, maximum length and maximum width of the ulcer was measured by ANOVA Kruskal-Wallis test and the Kruskal-Wallis post-hoc test. The change in the area of the ulcer, circumference, maximum length and width of the ulcer in all examined groups was statistically significant in relation to the beginning of treatment (Table 2).

30 days after the last treatment the average area of ulcers in patients who were treated with radial shockwave (group A) decreased significantly for $67.7 \%$ compared to the average surface area before the treatment. In patients who were treated with a focused shockwave (group B) the surface area was decreased by $63.5 \%$. However in patients with group $\mathrm{C}$ was decreased by $38.9 \%$. Table 3 .

In addition, we have divided groups (A, $B$ and $C$ ) for the inefficiency of superficial veins and superficial and deep veins. The highest percentage change in the ulcer area was obtained in group A with superficial veins failure $(82.8 \%)$, B with superficial veins failure $(71.0 \%)$, B with superficial and deep veins failure $(56.9 \%)$, A with insufficiency superficial and deep veins (50.7\%), C with superficial veins failure $(47.0 \%)$, C with superficial and deep veins failure (30.8\%).

The maximum length and the maximum width of the ulcer among patients from group A were also reduced, respectively, $58.2 \%$ and $59.6 \%$; and patients in group B respectively 
$46.2 \%$ and $48.7 \%$; and patients in group C respectively $24.6 \%$ and $30.6 \%$. Detailed data are shown in Table 3.

There was not statistically significant difference between the reduction in size of the ulcer, max length, max width and Gilman index for patients who were treated with radial shockwave (group A) and patients who were treated with focused shockwave (group B) and standard care (group C) after 4 weeks of treatment (Table 3).

After 8 weeks there was not statistically significant difference between the reduction in size of the ulcer patients who were treated with radial shockwave (group A) and patients who were treated with focused shockwave (group B). There was statistically significant difference between the reduction in size of the ulcer patients who were treated with radial shockwave (group A) and standard care (group C). There was not statistically significant difference reduction in the maximum length and maximum width of ulcers compared between groups $\mathrm{A}$ and $\mathrm{B}$. There was statistically significant difference reduction in the maximum length and maximum width of ulcers compared between groups $\mathrm{A}$ and $\mathrm{C}$ (Table 3 ).

Ulcer size reduction standardized for time is presented on Figure 4. Until the fourth treatment, the ulcer area decreased. Between the fourth and fifth treatments in group A and between the fourth and sixth treatments in group $B$ we observe an increase in the area of ulcers. We have observed a greater increase in ulcer area among patients who received radial shockwave therapy (group A) - 15\% compared to the ulcer area in patients who received focused shockwave therapy (group B) - 1\%. Then the surface area decreased successively in both groups. In group $\mathrm{C}$ the ulcer surface area was decreased till the end of the treatment.

Calculations the nonlinear approximation of treatment results demonstrated that to decrease wound surface area from start treatment by $50 \%$ needed 7.8 weeks of treatment in the group A (R-ESWT), 5.8 weeks of treatment in the group B (F-ESWT), and 18.2 in the group C (standard care), (Table 4, Figure 5).

Table 3. Relative percentage change area. length. width and Gilman index. $\mathrm{p}^{*}$ - ANOVA Kruskal-Wallis test; $\mathrm{p}$ - Kruskal-Wallis post-hoc test.

\begin{tabular}{|c|c|c|c|c|c|c|c|c|c|}
\hline & & At 4 wee & & & & At 8 weel & & & \\
\hline & Group & Average & SD & $\mathrm{p}$ & & Average & SD & $\mathrm{p}$ & \\
\hline \multirow[t]{3}{*}{ Relative percentage change in ulcer surface area [\%] } & R-ESWT (group A) & 46.3 & 31.9 & \multicolumn{2}{|l|}{$\mathrm{p}^{*}(\mathrm{~A} \ldots \mathrm{C})=0.121$} & 67.7 & 30.5 & $\mathrm{p}^{*}(\mathrm{~A} \ldots \mathrm{C})=$ & \multirow[t]{6}{*}{0.015} \\
\hline & F-ESWT (group B) & 53.7 & 33.6 & $\mathrm{p}(\mathrm{A} \mathrm{B})=1$ & & 63.5 & 30.7 & $\mathrm{p}(\mathrm{A} \mathrm{B})=1$ & \\
\hline & SWC (group C) & 31.7 & 24.7 & $\begin{array}{l}p(A C)=0.389 \\
p(B \text { C })=0.159\end{array}$ & & 38.9 & 27.1 & $\begin{array}{l}\mathrm{p}(\mathrm{A} \mathrm{C})=0.023 \\
\mathrm{p}(\mathrm{B} C)=0.084\end{array}$ & \\
\hline \multirow[t]{3}{*}{ Relative percentage change in max length [\%] } & R-ESWT (group A) & 26.0 & 24.9 & $\mathrm{p}^{*}(\mathrm{~A} \ldots \mathrm{C})=$ & \multirow[t]{3}{*}{0.42} & 58.2 & 35.9 & $\mathrm{p}^{*}(\mathrm{~A} \ldots \mathrm{C})=0.033$ & \\
\hline & F-ESWT (group B) & 36.6 & 30.6 & $\mathrm{p}(\mathrm{A} \mathrm{B})=1$ & & 46.2 & 36.6 & $\mathrm{p}(\mathrm{A} \mathrm{B})=0.93$ & \\
\hline & SWC (group C) & 22.1 & 19.5 & $\begin{array}{l}p(A C)=1 \\
p(B \text { C })=0.6\end{array}$ & & 24.6 & 21.5 & $\begin{array}{l}p(A C)=0.029 \\
p(B \text { C })=0.409\end{array}$ & \\
\hline \multirow[t]{3}{*}{ Relative percentage change in max width [\%] } & R-ESWT (group A) & 30.7 & 32.6 & $\mathrm{p}^{*}(\mathrm{~A} \ldots \mathrm{C})=$ & \multirow[t]{6}{*}{0.96} & 59.6 & 34.5 & $\mathrm{p}^{*}(\mathrm{~A} \ldots \mathrm{C})=$ & \multirow[t]{3}{*}{0.046} \\
\hline & F-ESWT (group B) & 31.9 & 40.1 & $\mathrm{p}(\mathrm{A} \mathrm{B})=1$ & & 48.7 & 34.5 & $\mathrm{p}(\mathrm{A} \mathrm{B})=0.788$ & \\
\hline & SWC (group C) & 26.7 & 18.3 & $\begin{array}{l}p(A \text { C })=1 \\
p(B \text { C })=1\end{array}$ & & 30.6 & 18.6 & $\begin{array}{l}p(A \text { C })=0.041 \\
p(B \text { C })=0.63\end{array}$ & \\
\hline \multirow[t]{3}{*}{ Gilman index $[\mathrm{cm}]$} & R-ESWT (group A) & 0.37 & 0.65 & $\mathrm{p}^{*}(\mathrm{~A} \ldots \mathrm{C})=1$ & & 0.75 & 1.07 & $\mathrm{p}^{*}(\mathrm{~A} \ldots \mathrm{C})=$ & \multirow[t]{3}{*}{0.283} \\
\hline & F-ESWT (group B) & 0.20 & 0.08 & $\mathrm{p}(\mathrm{A} \mathrm{B})=1$ & & 0.29 & 0.13 & $\mathrm{p}(\mathrm{A} \mathrm{B})=0.592$ & \\
\hline & SWC (group C) & 0.25 & 0.19 & $\begin{array}{l}p(A C)=1 \\
p(B \text { C })=1\end{array}$ & & 0.31 & 0.22 & $\begin{array}{l}\mathrm{p}(\mathrm{A} \text { C })=0.447 \\
\mathrm{p}(\mathrm{B} \mathrm{C})=1\end{array}$ & \\
\hline
\end{tabular}

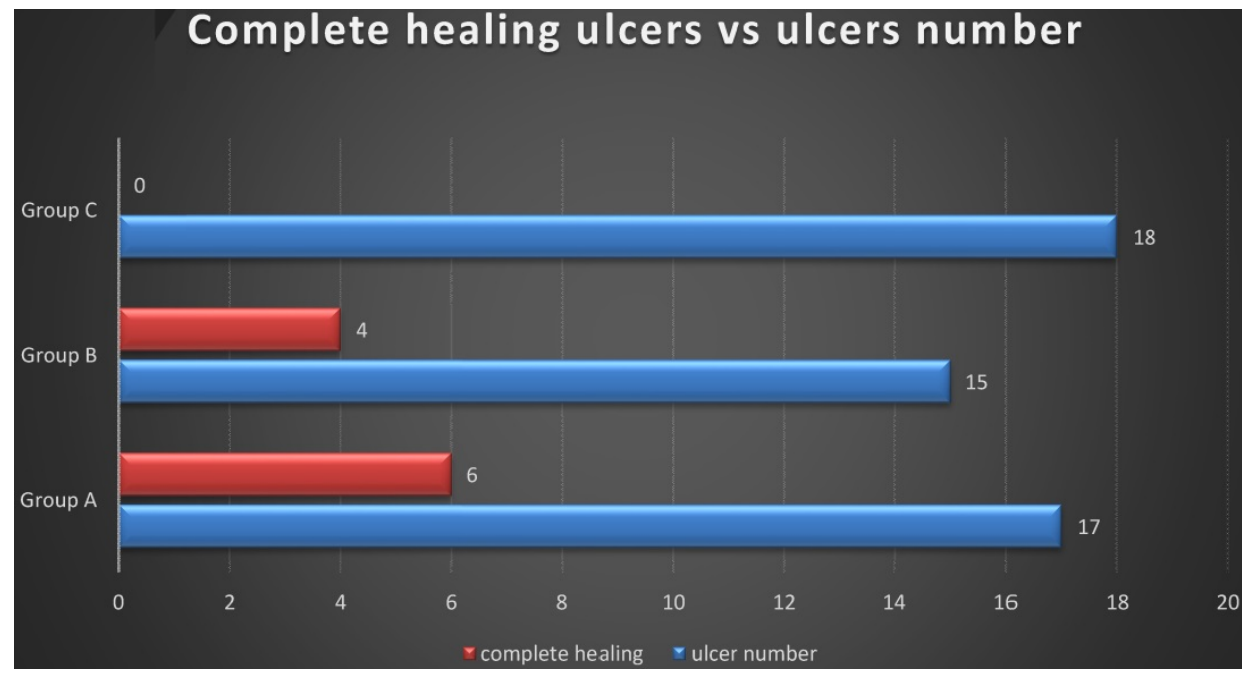

Figure 3. Complete healing ulcers vs ulcers number. Group A - R-ESWT; Group B - F-ESWT; Group C - SWC. 


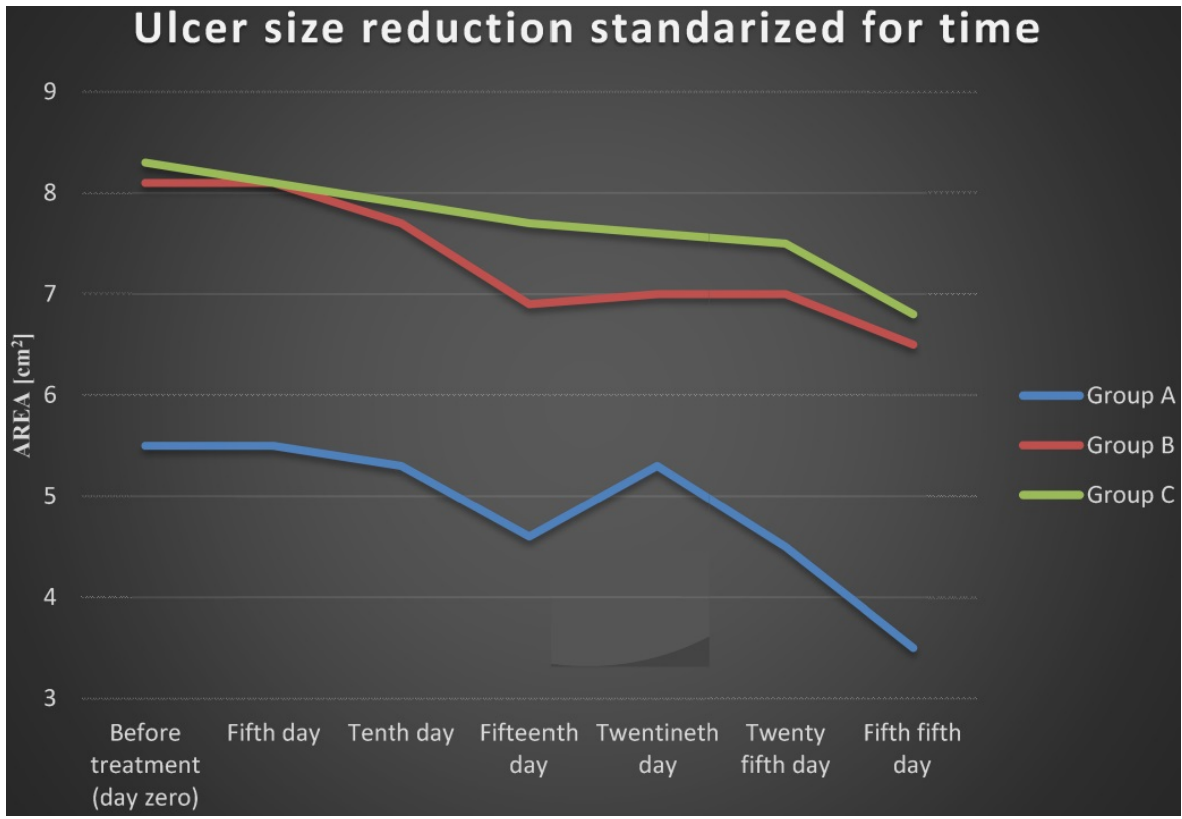

Figure 4. Ulcer size reduction standardized for time. Group A - R-ESWT; Group B - F-ESWT; Group C - SWC.

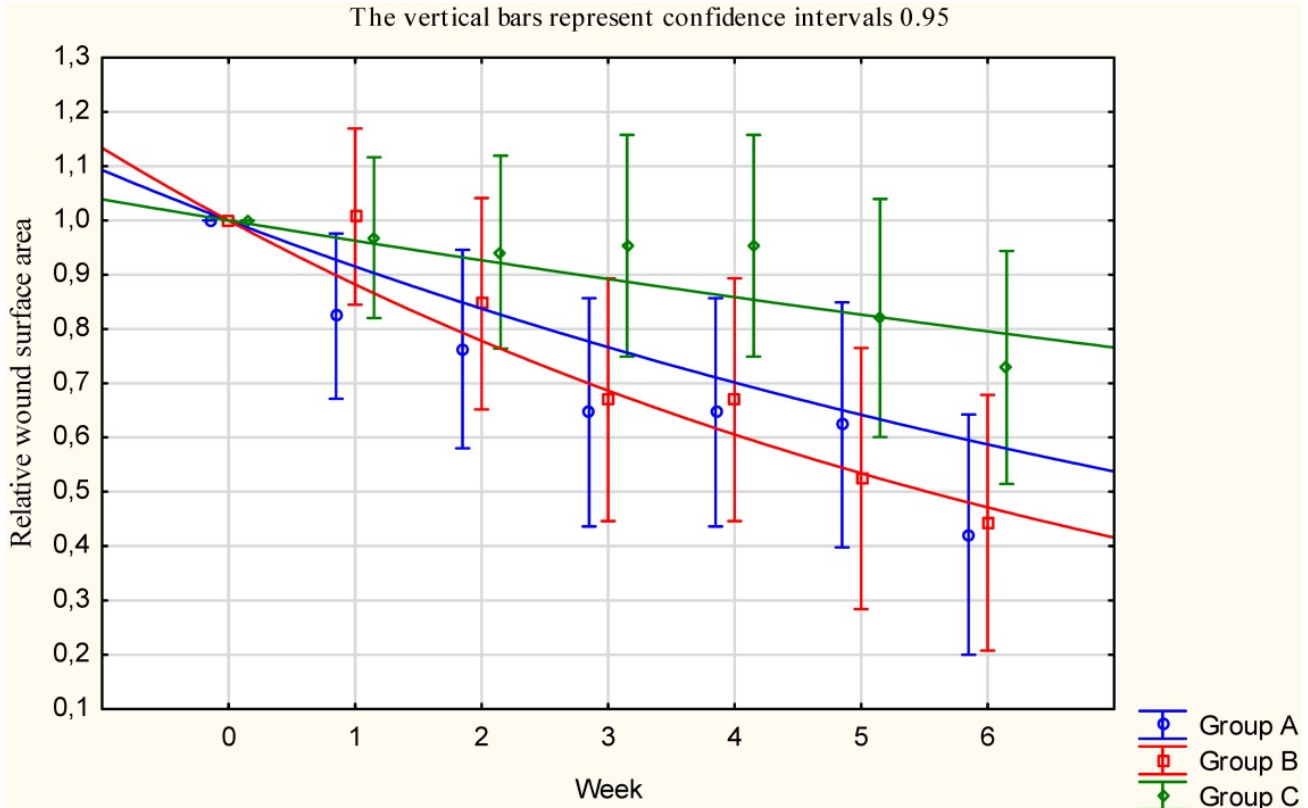

Figure 5. The nonlinear approximation of time needful for relative wound surface area to decrease by half from the beginning of treatment. Group A - R-ESWT; Group B - F-ESWT; Group C - SWC.

Table 4. The nonlinear approximation of time essential for wound area to decrease by half from baseline start treatment by $50 \%$.

\begin{tabular}{ll}
\hline Group & $\begin{array}{l}\mathrm{T}_{1 / 2}-\text { time essential for wound area to decrease by half from baseline start treatment. } \\
\text { [weeks] (CI - Confidence interval) }\end{array}$ \\
\hline R-ESWT (group A) & $7.8(95 \%$ confidence interval $0.05-0.21)$ \\
F-ESWT (group B) & $5.5(95 \%$ confidence interval $0.14-0.23)$ \\
SWC (group C) & $18.2(95 \%$ confidence interval $0.02-0.09)$ \\
\hline
\end{tabular}

Significance level of the differences between groups $\mathrm{p}(\mathrm{A} C)>0.05 ; \mathrm{p}(\mathrm{B} \mathrm{C})<0.05 ; \mathrm{p}(\mathrm{A} B)>0.05$.

\section{Discussion}

Statistical studies have been conducted in Western Europe among people suffering from venous disease indicate, that $0.5-4 \%$ of the adult population suffers from active venous leg ulcers. In less industrialized countries, the number of patients with venous ulcers is smaller. Statistics show that the frequency of ulcers increases with age, intensifying especially between 65 and 80 years of age. This is confirmed by our results. In group A, the average age 
of patients was 71.7 years, the youngest patient in this group was 59 years old and the oldest 81 . In group B, the average age was 69.1 years (the youngest 62 years, the oldest - 88). In group C, the average age was 67.4 years all groups were homogeneous in terms of age of the patients.

A review of the literature shows that the shockwave is rarely used method for treating venous leg ulcers. Application of a shockwave in the treatment of venous ulcers describe Jankovic [15], Schaden et al. [16], Saggini et al. [17], Steiger et al. [19] and Fioramonti et al [18]. More often it is used in the treatment of diabetic ulcers and burns. In addition, no description was found using radial shockwave (R-ESWT) in the treatment of venous ulcers, apart from the use of a focused or distributed shockwave (ESWT-F and D-ESWT). Only Jankovic [15] applied radial and focused shockwave to treat a 75 year old patient with diabetic foot ulcers and gangrene in both feet. In the first part of the study author combined both used types of shockwave, but does not documented values the waves. The second part study was started 4 days after the first applying. In this part of the treatment was used the radial shockwave pressure from 0.2 to $0.6 \mathrm{MPa}$ and $1000 \mathrm{impulses} / \mathrm{cm}^{2}$. The focused shockwave surface energy density was $0.07 \mathrm{~mJ} / \mathrm{mm}^{2}$ and 1000 impulses. In the third part was used only focused shockwave therapy $\left(0.03-0.10 \mathrm{~mJ} / \mathrm{mm}^{2}\right)$ and started one month after the second part finished. Next treatments were applied 2-4 weeks intervals in a total of 11 treatments. Healing after 11 months was completed.

For treatments using F-ESWT were the most commonly used values of the energy density is between 0.03 and $0.1 \mathrm{~mJ} / \mathrm{mm}^{2}$, and D-ESWT from 0.1 to $0.25 \mathrm{~mJ} / \mathrm{mm}^{2}$. The frequency used during treatments with the usage of F-ESWT (ulcers and venous diabetic) and D-ESWT (venous ulcers) is a 4 $\mathrm{Hz}$ [15-18] and $5 \mathrm{~Hz}$ for ulcers, bedsores and burns using F-ESWT and D-ESWT $[15,22]$. Some authors do not specify the frequency. The number of pulses per $\mathrm{cm}^{2}$ ranged between 100 impulses/ $\mathrm{cm}^{2}[14,15,17,22]$ to $2000 \mathrm{impulses} / \mathrm{cm}^{2}$ in the treatment of venous ulcers [18].

In our study we used radial shockwave R-ESWT pressure of $0.2 \mathrm{MPa}, 100$ impulses $/ \mathrm{cm}^{2}$ and frequency of $5 \mathrm{~Hz}$ and focused shockwave F-ESWT with a frequency of $5 \mathrm{~Hz}, 100 \mathrm{impulses} / \mathrm{cm}^{2}$, and 12 levels of intensity. Our selection of the parameters was not accidental. According to the producer's specifications for the device to treatment radial shockwave (Gymna Uniphy) our selection of the parameters of the shockwave corresponds to the surface energy density $0.17 \mathrm{~mJ} / \mathrm{mm}^{2}$. In contrast, the device generates focused shockwave (according to the Sound field measurement report for the Piezowave / F10G4 shockwave source Richard Wolf GmbH, Knittlingen, Germany December 5th, 2006) the so selected parameters produces the surface energy density $0.173 \mathrm{~mJ} / \mathrm{mm}^{2}$. The pressure measured during the peak generating focused shockwave is $35.6 \mathrm{MPa}$, but the mean pressure is at a level comparable to the pressure of $0.2 \mathrm{MPa}$ is produced when generating the radial shockwave. Chosen parameters of the shockwave both radial and focused enable us to compare properly the effects of two waves in the treatment of venous leg ulcers.

Unification of the surface energy density is a likely reason for the deficiency of differences between the treatment of venous leg ulcers with the use of radial and focused shockwave.

Used by us surface energy density $(0.17$ $\mathrm{mJ} / \mathrm{mm}^{2}$ ) is the average used by other researchers from $0.037 \mathrm{~mJ} / \mathrm{mm}^{2}$ to $0.25 \mathrm{~mJ} / \mathrm{mm}^{2}$. Similarly, at a frequency of 4 to $5 \mathrm{~Hz}$.

Schaden et al. [16] studied the efficacy of unfocused shockwave a low energy $\left(0.1 \mathrm{~mJ} / \mathrm{mm}^{2}\right.$ and frequency of $5 \mathrm{~Hz}$ ) for treating wounds of different etiologies (venous leg ulcers, pressure sores, burns and etc.) Two hundred eight subjects (99 women, 109 men) in aged range 18-95 were treated an average of three weeks at intervals of 1-2 weeks using the number of 100 to 1000 impulses $/ \mathrm{cm}^{2}$. Of the 25 patients with VLU were healing $36 \%$. Which confirms that we have received the results of treatment. In our study, we obtained a complete cure of ulcers in $35 \%$ of patients who were treated with the radial shockwave and $26 \%$ ulcers in patients, who were treated with a focused shockwave Figure 3.

For example, Sagginii et al. [17] assessed the efficacy of focused shockwave in treatment ulcers. A 30 patients were enrolled in the study treated with energy density of $0.037 \mathrm{~mJ} / \mathrm{mm}^{2}$ and 100 impulses $/ \mathrm{cm}^{2}$ and a frequency of $4 \mathrm{~Hz}$. The treatment group received performed every 2 weeks for a total of 4 to 10 sessions. Complete healing was observed in $36 \%$ of patients. Results were compared with the control group of 10 subjects.

Other researchers [18] conducted a clinical trial with 63 years old patient with two venous leg ulcers (initial area 3 and $8 \mathrm{~cm}^{2}$ ). For treatment on right leg used energy density $0.037 \mathrm{~mJ} / \mathrm{mm}^{2}$, frequency of $4 \mathrm{~Hz}$ and 100 impulse $/ \mathrm{cm}^{2}$; once a week over a period of 6 weeks until complete recovery. The number of treatments is the same as in the case of our study, the time interval between treatments is slightly different. Treating ulcer on the left leg by standard method (cleaning the wound with sterile gauze wrap) gave effect only a partial cure. This is consistent with our findings. 
Another researchers, Steiger et al. [19] treated one patient with ulcer (lasting six years, initial dimensions $15 \mathrm{~cm} \times 10 \mathrm{~cm}$ ). Unfocused shockwave was used with surface energy density $0.25 \mathrm{~mJ} / \mathrm{mm}^{2}$, frequency of $4 \mathrm{~Hz}$ and 2000 impulses $/ \mathrm{cm}^{2}$. The treatment was maintained once a week for 30 weeks. After 30 treatments the wound decreased to the dimensions of $3 \mathrm{~cm} \times 3 \mathrm{~cm}$. The complete healing was observed after skin transplantation.

Our observations and measurements were taken before treatment and 30 days after the last treatment. Other authors often continued to shockwave treatment until healing ulcers. This is particularly true test of one patient or description of the event, in which achieved $100 \%$ healing. In cases where the number of patients was higher ( 25 or 11 ) final observation was closely defined in time and the same for all participants in the study, which resulted in a decrease in the number of completely healed ulcers $(36 \%)$. This correlates with our results - 35\% (R-ESWT) and 26\% (F-ESWT).

None of the authors cited by us has not set Gilman ratio [22] (was originally used by the Hopkins and Jamiesen in 1983 [23]) which is a linear parameter determining the distance, that the edge of the wound defeated during treatment, towards the centre of the wound. In the case of wounds, that do not heal uniformly it is the average value. For ulcer from the group of patients, who were treated with radial shockwave Gilman ratio was $0.75 \pm 1.07 \mathrm{~cm}$, and for ulcer from the group of patients, who were treated with the focused shockwave was $0.29 \pm 0.13 \mathrm{~cm}$, and for control group was $0.31 \pm 0.22 \mathrm{~cm}$. In the case of wounds of various sizes similar coefficient Gilman shows that wounds are healing at almost the same rate.

In the study Polak et al. [24] used anodal (20 patients), cathodal (21 patients) and placebo (20 patients) electrical stimulation for treating non healing pressure ulcer. They also used calculations the nonlinear approximation of treatment results demonstrated that to decrease wound surface area from start treatment by $50 \%$ would needed 4.3 weeks of treatment in the anodal stimulation, 3.8 weeks in the cathodal stimulation, and 9.8 weeks in the placebo group. The same as in the case of our study, the time needed to decrease wound surface area by $50 \%$ it is twice as largest in the control group (placebo group).

Limitations. The small number (65) of patients with VLU that participated in three comparative groups was considered a limitation of this pilot study. In the future, results should be verified on a larger group of patients and analysed using parametric statistics. Results should be more long-term (follow-up observation of recurrence after 6 and 12 months) rather than the one month of therapy. In the future, the authors would like to provide quasi-shockwave therapy in control groups and present complete results. The future studies should be also extended to the laboratory test and analyses of the wound tissue samples collected by biopsy to find out some more basic foundations which translate to clinical effectiveness (translational medicine).

\section{Conclusion}

The treatment of venous leg ulcers used by us with the usage of radial and focused shockwave gave desired result in the form of reduction in ulcer surface.

Treatment of venous leg ulcers with shockwaves is more effective than the standard care.

Our researches show that there is no statistically significant difference between the use of radial and focused shockwaves in the treatment of venous leg ulcers.

The results of our study on the number of completely cured ulcers do not differ from those of the cited researchers.

\section{Acknowledgments}

This study was funded by statutory grant KNW-1-101/N/5/0.

\section{Competing Interests}

The authors have declared that no competing interest exists.

\section{References}

1. Dymarek R, Halski T, Ptaszkowski K, Slupska L, Rosinczuk J, Taradaj J. Extracorporeal shockwave therapy as an adjunct wound treatment: a systematic review of the literature. Ostomy Wound Manage. 2014; 60:26-39.

2. Zhan HT, Bush RL. A review of the current management and treatment options for superficial venous insufficiency. World J Surg. 2014; 38: 2580-8.

3. Lal BK. Venous ulcers of the lower extremity: Definition, epidemiology, and economic and social burdens. Semin Vasc Surg. 2015; 28: 3-5.

4. Ma H, O'Donnell TF Jr, Rosen NA, Iafrati MD. The real cost of treating venous ulcers in a contemporary vascular practice. J Vasc Surg Venous Lymphat Disord. 2014; 2 :355-61.

5. Alavi A, Sibbald RG, Phillips TJ, Miller OF, Margolis DJ, Marston W, Woo K, Romanelli M, Kirsner RS. What's new: Management of venous leg ulcers: Approach to venous leg ulcers. J Am Acad Dermatol. 2016; 74: 627-40.

6. Franks PJ, Barker J, Collier M, Gethin G, Haesler E, Jawien A, Laeuchli S, Mosti G, Probst S, Weller C. Management of patients with venous leg ulcers: Challenges and current best practice. J Wound Care. 2016; 25: 1-67.

7. Ścisło L. Life quality of patients with venous leg ulceration of lower extremities. Hygeia Public Health 2015; 50: 149-154.

8. Collins L, Seraj S. Diagnosis and Treatment of Venous Ulcers. Am Fam Physician. 2010; 81: 989-996.

9. Taradaj J, Franek A, Blaszczak E, Polak A, Chmielewska D, Krol P, Dolibog P. Using Physical Modalities in the Treatment of Venous Leg Ulcers: A 14-year Comparative Clinical Study. Wounds. 2012; 24: 215-26.

10. Dolibog P, Franek A, Taradaj J, Polak A, Dolibog P, Blaszczak E, Wcislo L, Hrycek A, Urbanek T, Ziaja J, Kolanko M. A randomized, controlled clinical pilot study comparing three types of compression therapy to treat venous leg ulcers in patients with superficial and/or segmental deep venous reflux. Ostomy Wound Manage. 2013; 59: 22-30.

11. Speed C. A systematic review of shockwave therapies in soft tissue conitiones: focusing on the evidence. Sports Med. 2014; 48: 1538-1542.

12. Zhang L, Fu XB, Chen S, Zhao ZB, Schmitz C, Weng CS. Efficacy and safety of extracorporeal shockwave therapy for acute and chronic soft tissue wounds: A systematic review and meta-analysis. Int Wound J. 2018; doi: 10.1111/iwj.12902 
13. Zhang L, Weng C, Zhao Z, Fu X. Extracorporeal shockwave therapy for chronic wounds: A systematic review and meta-analysis of randomized controlled trials. Wound Repair Regen. 2017; 25: 697-706.

14. Ogden JA, Tóth-Kischkat A. Principles of shockwave therapy. Clin Orthop Rel Res. 2001; 387, 8-17.

15. Jankovic D. Case study: shockwave treatment of diabetic gangrene. Int Wound J. 2011; 8: 206-209.

16. Schaden W, Thiele R, Kölpl C, Pusch M, Nissan A, Attinger CE, Maniscalco-Theberge ME, Peoples GE, Elster EA, Stojadinovic A. Shockwave therapy for acute and chronic soft tissue wounds: a feasibility study. Jurnal Of Surgical Research. 2007; 143: 1-12.

17. Sagginii R, Figus A, Troccola A, Cocco V, Saggini A, Scuderi N. Extracorporeal shockwaves therapy for management of chronic ulcers in the lower extremites. Ultrasound In Medicine And Biolog. 2008; 34: 1261-71.

18. Fioramonti P, Onesti MG, Finoi P, Fallico N, Scuderi N. Extracorporeal shockwaves therapy for the treatment of venus ulcers in the lower limbs. Ann Ital Chir. 2012; 83: 41-4.

19. Steiger M, Schmid JP, Bajrami S, Hunziker T. Extracorporeal shockwave therapy as a treatment of non-healing chronic leg ulcer. Hautarzt. 2013; 64: 443-6.

20. Wang CJ, Kuo YR, Wu RW, Liu RT, Hsu CS, Wang FS, Yang KD. Extracorporeal shockwave treatment for chronic diabetic foot ulcers. Jurnal of Surgical Research. 2009; 152: 96-103.

21. Aschermann I, Noor S, Venturelli S, Sinnberg T, Mnich CD, Busch Ch. Extracorporal shockwaves activate migration, proliferation and inflammatory pathways in fibroblasts and keratinocytes, and improve wound healing in an openlabel, single-arm study in patients with therapy-refractory chronic leg ulcers. Cell Physiol Biochem. 2017; 41: 890-906.

22. Gilman T. Parameter for measurement of wound closure. Wounds. 1990; 2: 95-101.

23. Gowland Hopkins NF, Jamieson CW. Antibiotic concentration in the exudate of venous ulcers: the prediction of ulcer healing rate. Br J Surg. 1983; 70: 532-34.

24. Polak A, Kucio C, Kloth LC, Paczula M, Hordynska E, Ickowicz T, Blaszczak E, Kucio E, Oleszczyk K, Ficek K, Franek A. A randomized, controlled clinical study to assess the effect of anodal and cathodal electrical stimulation on periwound skin blood flow and pressure ulcer size reduction in persons with neurological injuries. Ostomy Wound Manage. 2018; 64: 10-29. 